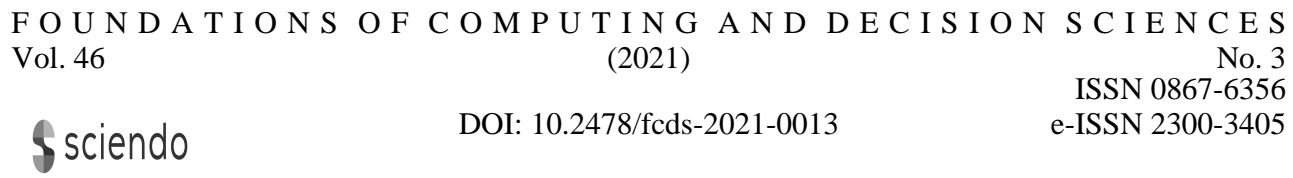

\title{
An Introduction to the Special Issue on Numerical Techniques Meet with OR - Part II
}

\author{
Burcu Gürbüz *, Gerhard-Wilhelm Weber ${ }^{\dagger}$
}

\begin{abstract}
The special issue: "Numerical Techniques Meet with OR" of the Foundations of Computing and Decision Sciences consists of two parts which are of the main theme of numerical techniques and their applications in multi-disciplinary areas. The first part of this special issue was already collected in the FCDS Vol. 46 , issue 1. In this second part of our special issue editorial, a description of the special issue presents numerical methods which can be used as alternative techniques for Scientific Computing and led Operational Research applications in many fields for further investigation.
\end{abstract}

Scientific computing is an important research topic that supports many fields to develop outcomes. The numerical methods and computing algorithms based on mathematics bring new ideas to many research topics, ranging from numerical and symbolic or algebraic computations, parallel or distributed processing, inverse problems or image processing, to machine learning and visualization. It also contributes to computational science and engineering and continues to broaden new fields in Operational Research. From the historical point of view, numerical scientific computing has been of great importance to the foundation of Computer Science. As a good example, the first mechanical calculator, also known as the first programmable computer Z1, was created by German Konrad Zuse for solving systems of linear equations to build a bridge between civil engineering designs with scientific computation in 1938. On the other hand, Harvard Mark I (IBM Automatic Sequence Controlled Calculator; ASCC) was called Mark I by Harvard University's staff and developed by Howard Aiken who was a scientist curious about the solutions of systems of ordinary differential equations. From those days onward, the quality of the computations have been dramatically increased and the studies in different science fields were developed. In

\footnotetext{
*Johannes Gutenberg-University of Mainz, Germany; ORCID 0000-0002-4253-5877, burcu.gurbuz@uni-mainz.de

†Poznan University of Technology, Poland; METU, Ankara, Turkey, ORCID 0000-0003-0849-7771, gerhard.weber@put.poznan.pl
} 
brief, numerical techniques of scientific computing are the compilation of theories together with techniques and tools which maintain approximation in order on a modern computer to solve mathematical models of problems from science and engineering, and notably from Operational Research. With the help of numerical approaches, we can visualize our findings, which emerge real-world applications in real life. In a sense, with the support of numerical techniques, mathematical applications, management of organized systems, and decision-making mechanisms are improved and they lead applied sciences to play a key role in real-world phenomena. Thus, by including these topics in our special issue, we contribute to applied sciences with the help of outstanding research studies. The special issue consists of thirteen papers that reveal various numerical applications based on real-world problems. The collection of these studies give the readers an enhanced well-understanding in many fields, including modern Operational Research.

As the Guest Editors, we genuinely thank all the contributors to our special issue. Our superior reviewers provided fundamental comments to the authors which gave extraordinary support to them in order to improve their research articles. During this period of time, we have had a great opportunity to work with a magnificent team of FCDS. We cordially thank them who gave us a great chance to bring our ideas to life in a very friendly and genial environment. We would like to send our deepest thanks to Prof. Dr. Jerzy Stefanowski, the Editor-in-Chief of FCDS, and Dr. Marcin Radom, the Managing Editor of FCDS, as well as all the Editorial Board members of FCDS. Consequently, we would like to thank all the prestigious contributed authors who made this project real with their hard and devoted work and commitment.

\section{References}

[1] Aydın, T. A., Ayazoğlu, R., and Kocayiğit, H. (2021). Morgan-Voyce Polynomial Approach for Quaternionic Space Curves of Constant Width. Foundations of Computing and Decision Sciences, 46(1), 71-83.

[2] Barman, H., Pervin, M., Roy, S.K., and Weber, G.W. (2021). Back-ordered inventory model with inflation in a cloudy-fuzzy environment. Journal of Industrial and Management Optimization, 17(4), 1913.

[3] Belkacem, S.N. (2021). An Algorithm for Choosing, Ordering a New Criteria of a Bi-Objective Flow Problem. Foundations of Computing and Decision Sciences, 46(1), 11-26.

[4] Das, S.K., Pervin, M., Roy, S.K., Weber, G.W. (2021). Multi-objective solid transportation-location problem with variable carbon emission in inventory management: A hybrid approach. Annals of Operations Research, 1-27, online first. DOI: $10.1007 / \mathrm{s} 10479-020-03809-\mathrm{z}$

[5] Ergün, S., Usta, P., Alparslan Gök, S.Z., and Weber, G.W. (2021). A game theoretical approach to emergency logistics planning in natural disasters. Annals of Operations Research, 1-14, online first. DOI: 10.1007/s10479-021-04099-9 
[6] Gander, W., Gander, M.J., and Kwok, F. (2014). Scientific Computing-An Introduction using Maple and MATLAB, Springer Science and Business.

[7] Gogodze, J. (2021). Revealed Comparative Advantage Method for Solving Multicriteria Decision-making Problems. Foundations of Computing and Decision Sciences, 46(1), 85-96.

[8] Goli, A., Babaee Tirkolaee, E., and Weber, G.W. (2021). An integration of neural network and shuffled frog-leaping algorithm for CNC machining monitoring. Foundations of Computing and Decision Sciences, 46(1), 27-42.

[9] Grobelny, J., Michalski, R., and Weber, G.W. (2021). Modeling human thinking about similarities by neuromatrices in the perspective of fuzzy logic. Neural Computing and Applications, 33(11), 5843-5867.

[10] Gürbüz, B., and Weber, G.W. (2021). Editorial-Preface to the Special Issue on Numerical Techniques Meet with OR. Foundations of Computing and Decision Sciences, 46(1), 3-10.

[11] Gürbüz, B. (2021). A computational approximation for the solution of retarded functional differential equations and their applications to science and engineering. Journal of Industrial and Management Optimization. Online first. DOI: 10.3934/jimo.2021069

[12] Gürbüz, B., Mawengkang, H., Husein, I., and Weber, G.W. (2021). Rumour propagation: an operational research approach by computational and information theory. Central European Journal of Operations Research, 1-21. Online first. DOI: 10.1007/s10100-020-00727-0

[13] Gürbüz, B. (2021). A numerical scheme for the solution of neutral integrodifferential equations including variable delay. Mathematical Sciences, 1-9. Online first. DOI: 10.1007/s40096-021-00388-3

[14] Gürbüz, B. (2020). Hybrid approximation for solutions of high-order integrodifferential equations including variable delay. Journal of Physics: Conference Series 1641(1) 012062. IOP Publishing.

[15] Hatipoğlu, V.F. (2021). Understanding the Impact of COVID-19 on Global Financial Network Using Graph Based Algorithm: Minimum Spanning Tree Approach. Foundations of Computing and Decision Sciences, 46(1), 111-123.

[16] Lemenkov, V., and Lemenkova, P. (2021). Using TeX Markup Language for 3D and 2D Geological Plotting. Foundations of Computing and Decision Sciences, 46(1), 43-69.

[17] Lotfi, R., Mehrjerdi, Y. Z., Pishvaee, M. S., Sadeghieh, A., and Weber, G.W. (2021). A robust optimization model for sustainable and resilient closed-loop supply chain network design considering conditional value at risk. Numerical Algebra, Control and Optimization, 11(2), 221. 
[18] Saputra, D., Gürbüz, B., and Haryani, H. (2021). Android-Based Animation for Chemical Elements and Experiments as an Interactive Learning Media. Journal of Science Learning, 4(2), 185-191.

[19] Tirkolaee, E. B., Abbasian, P., and Weber, G.W. (2021). Sustainable fuzzy multitrip location-routing problem for medical waste management during the COVID19 outbreak. Science of the Total Environment, 756, 143607.

[20] Uçar, E., Uçar, S., Evirgen, F., and Özdemir, N. (2021). Investigation of ECigarette Smoking Model with Mittag-Leffler Kernel. Foundations of Computing and Decision Sciences, 46(1), 97-109.

[21] Z3-FOLDOC. foldoc.org. (2020). https://www.computerhope.com/issues/ch000984.htm. 